\title{
Effect of Trapping Method on Leukocyte Profiles of Black-Chested Spiny-Tailed Iguanas (Ctenosaura melanosterna): Implications for Zoologists in the Field
}

\author{
Andrew K. Davis, ${ }^{1}$ Leslie E. Ruyle, ${ }^{1,2}$ and John C. Maerz ${ }^{3}$ \\ ${ }^{1}$ Odum School of Ecology, The University of Georgia, Athens, GA 30602, USA \\ ${ }^{2}$ Applied Biodiversity Science NSF-IGERT Program, Texas A\&M University, College Station, TX 77843, USA \\ ${ }^{3}$ D.B. Warnell School of Forestry and Natural Resources, The University of Georgia, Athens, GA 30602, USA
}

Correspondence should be addressed to Andrew K. Davis, akdavis@uga.edu

Received 23 June 2011; Accepted 14 July 2011

Academic Editors: A. Ramirez-Bautista and V. Tilgar

Copyright ( $) 2011$ Andrew K. Davis et al. This is an open access article distributed under the Creative Commons Attribution License, which permits unrestricted use, distribution, and reproduction in any medium, provided the original work is properly cited.

\begin{abstract}
When wild animals are captured for zoological research, researchers must choose a method of capture, and often this can be some form of passive, baited cage trap, or a direct capture with nets or nooses. If information on basal levels of circulating leukocytes is a goal, these two methods may provide different information, since recent evidence indicates that animals that enter cage traps experience stress, and, elevated stress hormones are known to alter leukocyte numbers in circulation by lowering lymphocyte and raising heterophil numbers. We tested this idea using a study of Black-chested Spiny-tailed iguanas (Ctenosaura melanosterna), which were captured using cage traps $(n=23)$ and noose $(n=27)$. Based on cell counts made from blood smears, iguanas caught with cage traps had significantly greater relative and absolute numbers of heterophils and higher heterophil-lymphocyte (H-L) ratios than those captured by noose. Cage-trapped animals also had a nonsignificant reduction in lymphocyte numbers. Similar trends were observed in animals captured with both methods. These patterns are consistent with the effects of stress hormones on white blood cell distributions and indicate that caution must be taken in interpreting leukocyte data from studies of wild animals captured with cage traps.
\end{abstract}

\section{Introduction}

Researchers of wild animals are increasingly conducting projects that include measures of circulating hormone levels or the distributions and abundances of white blood cells as a means to evaluate health or stress in animal populations. While the specific goals of the projects may vary, they all have in common certain methodological approaches; animals are captured in the wild and a suite of samples (tissue, blood) and/or measurements are collected from them that allow the investigator to gauge the health state of the population or to assess health- or immune-related parameters (e.g., [1-3]). One of the most commonly assessed pieces of information in such projects is data on the numbers of circulating leukocytes (white blood cells) in the animals, which can be gathered from examination of stained blood smears on microscope slides. As the primary line of defense against foreign path- ogens, leukocytes make up an important component of the innate or nonspecific immune system [4-6], thus their concentrations are often of particular interest. Indeed, interest in obtaining data on leukocyte numbers is rapidly growing among animal ecologists (e.g., [7-11]). However, one aspect that investigators must consider in any research project involving capture of wild animals is the method of capture $[12,13]$. This may be particularly relevant when multiple capture techniques are used across studies.

Two recent reports have described the effects of trapping on basal levels of stress hormones in wild animals; Fletcher and Boonstra [14] examined populations of meadow voles (Microtus pennsylvanicus), while Lynn and Porter [15] studied house sparrows (Passer domesticus). In both cases, levels of plasma stress hormones were compared in animals captured with baited cage traps (where animals freely enter and remain for some period of time before sampling) to 


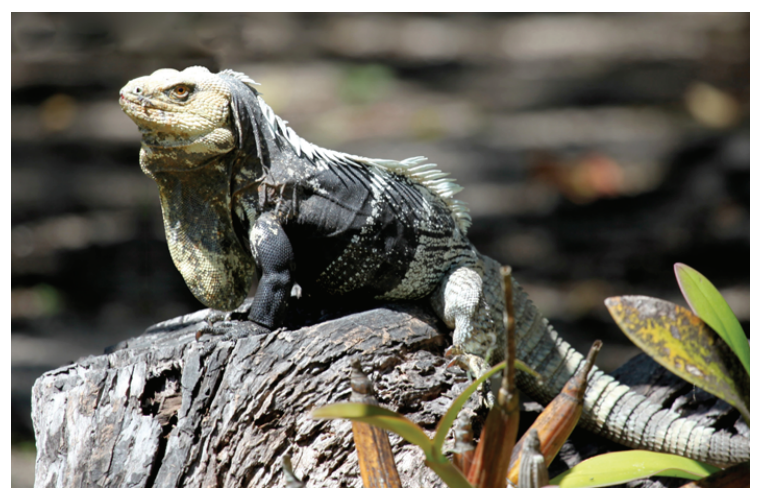

Figure 1: Black-chested Spiny-tailed Iguana (Ctenosaura melanosterna). Photo taken by LER.

those captured and sampled directly (i.e., immediately). Both studies show baseline stress hormone levels that are significantly higher in the cage-trapped animals than the directly sampled animals, which demonstrates that animals perceive the cage environment as "stressful," even if they appear visibly calm in the traps [15]. Moreover, Fletcher and Boonstra [14] discovered that stress levels remained high among all cage-trapped animals, regardless of the amount of time spent in traps. This result has considerable implications for all projects involving immune measures, especially when one considers how elevations in stress hormones can lead to alterations in the normal populations of leukocytes in circulation (reviewed in [16]); it then stands to reason that animals that remain in traps before blood sampling could in the end have altered leukocyte profiles that reflect this stress effect. Specifically, elevated stress hormones can lead to increases in circulating neutrophils (in mammals and amphibians) or heterophils (in reptiles and birds), and decreases in circulating lymphocytes, and this has been empirically demonstrated in all vertebrate taxa [16]. Given the widespread use of baited cage traps in wildlife research, and the importance of correct interpretations of leukocyte data for this research, be it ecological or veterinarian, this issue clearly warrants attention.

This paper reports on the effects of capture technique on the leukocyte profiles of the Black-chested Spiny-tailed iguana (Ctenosaura melanosterna, Figure 1), which is a medium-sized lizard that has a narrow geographic range limited to the Rio Aguan Valley in north-central Honduras and the Cayos Cochinos (Hog Islands) archipelago 17 kilometers off the country's northern coastline [17]. Specifically, we tested the hypothesis that compared to iguanas captured by a noose and sampled immediately, iguanas captured in baited traps would have higher numbers of circulating heterophils and lower numbers of circulating lymphocytes, resulting in a higher heterophil: lymphocyte ratio and reflecting elevated stress due to cage capture. This study was part of a larger project using a variety of capture techniques to measure C. melanosterna demography and health across a range of natural and human altered environments.

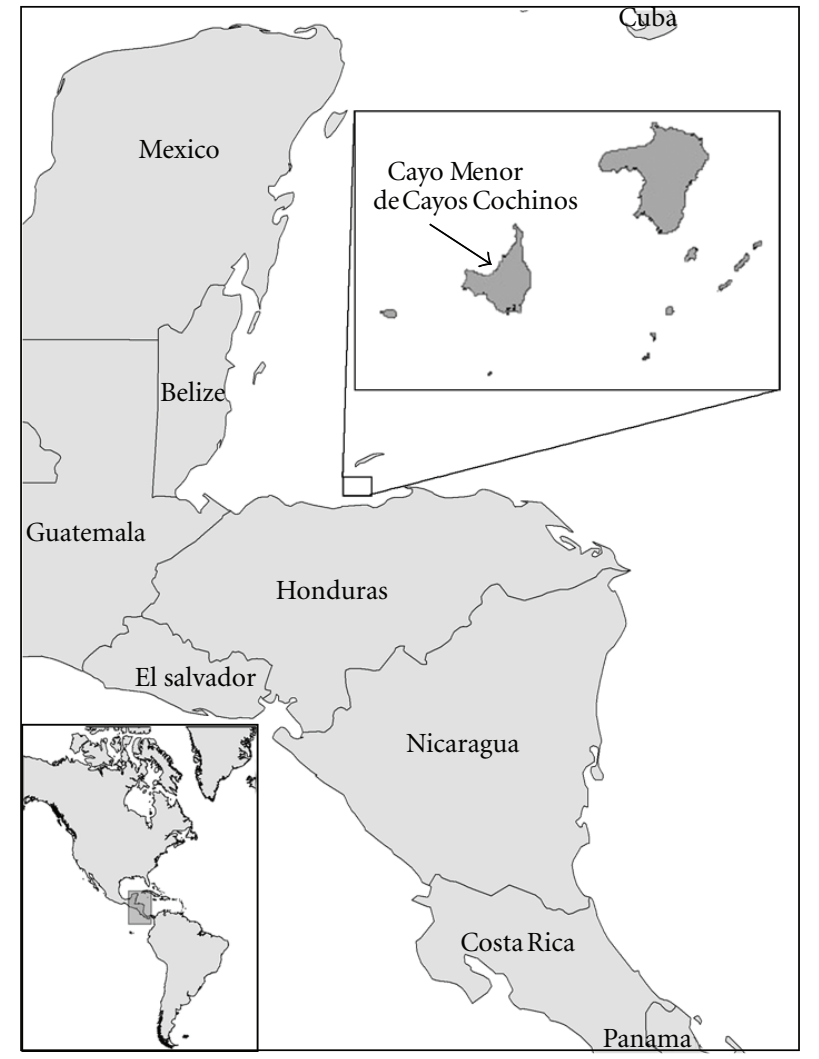

Figure 2: Map of the study site, the Honduran island, Isla Cayo Cochino Menor $\left(15.97^{\circ} \mathrm{N}, 86.47^{\circ} \mathrm{W}\right)$.

\section{Methods}

2.1. Study Site. For this study, we used animals captured from the island of Cayo Cochino Menor (Little Hog Island) in the Cayos Cochinos archipelago off the Atlantic coast of Honduras (Figure 2). The Cayos Cochinos archipelago is made up of two larger rock islands and several small cays approximately 17 kilometers from the mainland and $30 \mathrm{~km}$ south of the largest Bay Island, Roatan. Cayo Cochino Menor has an area of approximately 65 hectares and is 1.5 kilometers from north to south and 1.1 kilometers east to west with a highest elevation point of $140 \mathrm{~m}$. There are no permanent residents on the island, except employed staff that stay on the island to facilitate research and other groups visiting the island.

The iguanas used in this study all came from the immediate area around the research station ( $\sim 2 \mathrm{ha}$ in area), which is comprised mostly of beach, sloping scrub forest, and housing structures. The two-hectare study area where we captured iguanas is mostly open habitat with beach, buildings, and low-growing herbs as the dominant landscape features. The edges of the study area open either into beach margin habitat or into the interior of the island of evergreen oak forest where Quercus compared to oleoides is the dominant tree species [18]. Between twenty and forty years ago, the beach area was artificially expanded in order to create space for buildings and a small plane landing strip (A. Solis pers. comm.). The field is currently maintained as a helicopter-landing pad 


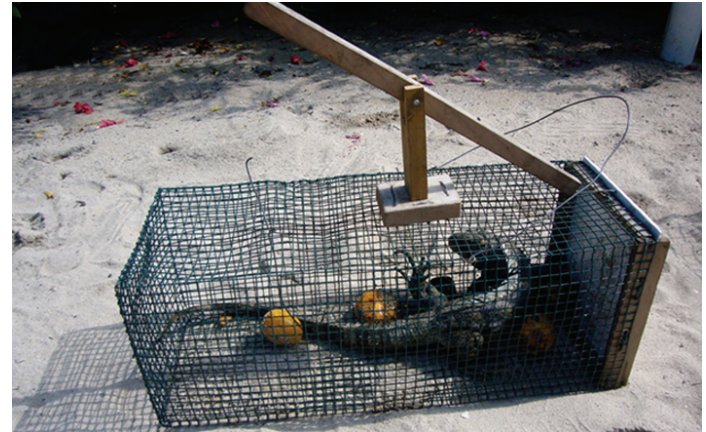

(a)

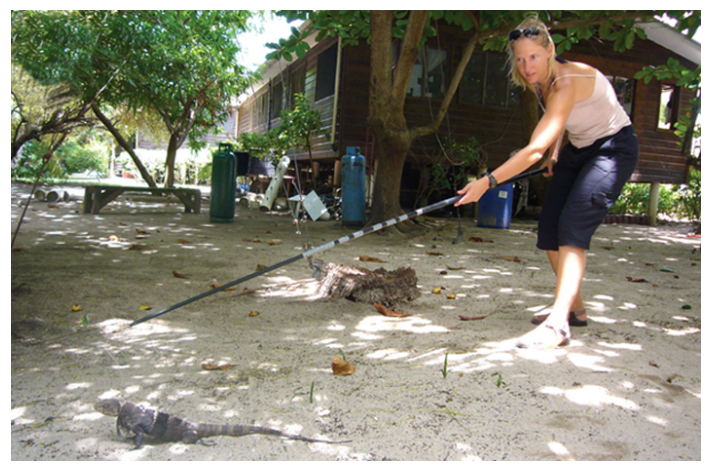

(b)

Figure 3: Photographs of the two methods of capturing iguanas in this study, a baited, walk-in cage (a) which was set up at 8 am each morning and checked at noon and $4 \mathrm{pm}$, and direct capture of the animal with a noose (b).

(L. Ruyle pers. obs.). Cultivated fruit trees, specifically mango (Mangifera spp.) and lime (Citrus spp.) were planted (A. Solis pers. comm.) for local consumption at the same time as the beach expansion. In 1995, well after the expansion, Bermingham et al. [18] conducted a survey of the flora of the area. They recorded the common herbs around the station area as beach morning glory (Ipomoea pescaprae), Canavalia (Fabaceae-Papilionoid), Wedelia (Asteraceae), and Cenchrus (Poaceae). The beach margin of the study area is composed of trees such as coconut palm (Cocos nucifera), sea grape (Coccoloba uvifera), tropical almond (Terminalia catappa), and Thespesia populnea [18]. Several of the buildings are surrounded by Hibiscus pernambucensis that iguanas use for food and cover (L. Ruyle pers. obs.). Iguanas in the study area use both trees and buildings for refugia. Currently, the research station maintains the area around the buildings by cutting back vegetation and pruning trees, which also helps keep the area open.

2.2. Trapping Iguanas. Iguanas were captured in the months of May, June, and July of 2010. This time frame largely follows the egg-laying period for this species in April and May [17]. Two capture methods were used. One was wire mesh traps baited with mangoes and canned cat food or tuna (Figure 3(a)). Traps were opened and baited each morning at $0800 \mathrm{~h}$ and were checked at $1200 \mathrm{~h}$ and $1600 \mathrm{~h}$. Thus, lizards were never left in a trap for longer than four hours. Traps were then closed at the end of each day. To remove animals from traps, we covered one end of the trap with an iguana bag and flushed them from the trap into the bag. Animals were taken out of the bag to collect measurements and a blood sample. The second capture method was by noose (Figure 3(b)), which a standard method for catching lizards $[19,20]$. We used 20' Black Widow Crappie poles with nooses made of fishing line to capture animals. Our technique was to stalk the lizards, place the noose over their heads, and pull up on the pole to close the noose. Once animals were securely noosed, we walked them back to the laboratory (less than five minutes) to take measurements and obtain blood samples. We collected $0.2 \mathrm{cc}$ of blood from the caudal vein of each iguana using a $1.0 \mathrm{cc}$ syringe and needle. We placed one drop of blood from the needle onto the slide and created a smear using the standard two-slide wedge technique [21]. The remainder of the blood was stored for additional studies. Blood smears were air-dried, stored, and transported to the lab at the University of Georgia.

Iguanas were often captured with considerable injuries, such as gouges to the tails, missing toes, or gaping wounds, presumably from aggressive encounters with conspecifics. In addition, iguanas sometimes became injured after capture in traps, by damaging their long toenails in the cage or scraping their noses on the cage wire. Because of the possibility that such injuries can lead to alterations in leukocyte profiles, iguanas with visible injuries were not included in this study.

2.3. Reading Blood Smears. Giemsa-stained smears were examined with a light microscope under 1000x (oil) following standard protocols used in our lab [22-24]. Briefly, slides were scanned in a zig-zag pattern so that as much of the smear was sampled as possible, and in each field of view all leukocyte types were counted until at least 100 leukocytes had been tallied. Only fields of view with an even monolayer of erythrocytes were considered. At this magnification, fields of view had an average of 169 ( \pm 41 SD) erythrocytes based on counts from 10 random fields of view. Leukocytes were identified as lymphocytes, heterophils, basophils, monocytes, and azurophils following Thrall [25] and Alleman et al. [26]. Eosinophils were not observed, which was not surprising since iguanas typically have extremely low numbers of this cell [27-29]. Azurophils were pooled with monocytes [26]. When cell counting was complete the relative number of each cell type was calculated out of the 100 cells, and heterophillymphocyte ratios were calculated for each animal based on the relative numbers of both cells observed. An estimate of the absolute number of each cell type was calculated as the number of cells per 2000 erythrocytes [24]. This method of estimating cell numbers differs from the conventional veterinary procedure involving counts from whole blood using a hemocytometer [25, 30], but obtaining large samples of whole blood was not a goal of the primary iguana study, nor was it logistically feasible to perform this procedure at the field site. Moreover, the focus of the current paper is on identifying the directional changes in cell counts based on the trapping method, which should hold no matter how the counts are conducted. 
TABle 1: Summary of relative leukocyte counts and heterophil-lymphocyte ratios of Black-chested Spiny-tailed Iguanas (Ctenosaura melanosterna) based on the method of capture. See text for description of capture methods. Eosinophils were not observed and azurophils were pooled with monocytes. Asterisks indicate level of significance in Student's $t$-tests that compared means from both capture methods.

\begin{tabular}{|c|c|c|c|c|c|}
\hline Trap method & \% lymphocytes & $\%$ heterophils & \% basophils & $\%$ monocytes & $\mathrm{H}-\mathrm{L}$ ratio \\
\hline Noose $(N=27)$ & $75.2( \pm 14.9)$ & $13.1( \pm 11.3)$ & $4.2( \pm 2.4)$ & $7.5( \pm 5.0)$ & $0.22( \pm 0.25)$ \\
\hline Cage trap $(N=23)$ & $58.6( \pm 16.1)^{* *}$ & $25.6( \pm 13.1)^{* *}$ & $4.2( \pm 3.1)$ & $11.6( \pm 5.9)^{*}$ & $0.53( \pm 0.41)^{* *}$ \\
\hline Combined $(N=50)$ & $67.5( \pm 17.4)$ & $18.9( \pm 13.6)$ & $4.2( \pm 2.7)$ & $9.4( \pm 5.8)$ & $0.36( \pm 0.37)$ \\
\hline
\end{tabular}

${ }^{* *} P<0.001$.

$* P<0.05$.

2.4. Data Analysis. Heterophil-lymphocyte ratios and estimated counts of each individual cell type (heterophils, lymphocytes, basophils, and monocytes) were log-transformed $(+1)$ prior to statistical tests to approximate normal distributions. Since initial comparisons of these blood cell data from males versus females revealed no difference (Student's $t$-tests, $P>0.05$ for all tests), data from both sexes were pooled. Then, both relative and absolute cell counts, as well as $\mathrm{H}-\mathrm{L}$ ratios were compared between all iguanas captured by cage and those captured by noose using Student's $t$-tests. In addition, $\mathrm{H}$-L ratios were compared in a subset of individuals ( $n=10$ ) that had been captured with both the noose and cage, using paired $t$-tests. All analyses in this study were conducted using Statistica 6.1 software [31].

\section{Results}

3.1. General. A total of 50 injury-free iguanas were captured and sampled for this study, 23 by cage trap and 27 by noose. There were 19 females and 8 males captured by noose and 16 females and 7 males captured by cage trap. These sex ratios were not statistically different between trapping methods (Chi-square test, $\chi=0.004, P=0.950)$. The iguanas ranged in body size (SVL) from $11-37 \mathrm{~cm}$, and males $(\bar{x}=26.4 \mathrm{~cm})$ were significantly larger than females $(\bar{x}=23.0 \mathrm{~cm}, t=$ $-2.24, P=0.030)$. In addition, there were 10 iguanas that were captured twice, using both the noose and the cage.

3.2. Relative Leukocyte Counts and H-L Ratio. The mean percentages of all leukocyte types is shown in Table 1, with the data grouped by capture method. Considering all 50 animals, lymphocytes and heterophils made up the majority of leukocytes $(86.4 \%)$ in this species, with lymphocytes being most common (67.5\%). However, there were notable differences in the leukocyte profiles of noosed versus cagetrapped iguanas. As predicted, the animals captured with cage traps had significantly lower percentages of lymphocytes $(t=3.76, d f=48, P=0.0004)$, and higher percentages of heterophils $(t=-3.61, d f=48, P=0.0007)$ and monocytes/azurophils $(t=-2.61, d f=48, P=0.012)$ than those captured by noosing. Moreover, as predicted, the mean heterophil-lymphocyte ratio of cage-trapped iguanas was greater (twice as high) than the mean heterophil-lymphocyte ratio of noosed animals $(t=-3.30, d f=48, P=0.0017$; Table 1). Similarly, in the subset of individuals $(n=10)$ that were captured using both methods, the $\mathrm{H}$-L ratios obtained after capture with cage traps were higher on average than that found after noosing, although the effect was marginally significant (paired $t$-test, $t=-2.18, d f=9, P=0.056$ ).

3.3. Estimated Leukocyte Counts. Similar to the pattern with the relative cell counts, iguanas captured in cage traps had significantly greater estimated (absolute) numbers of heterophils than those captured by noosing $(t=-3.43, d f=$ $48, P=0.001$; Figure $4(a))$. In fact, on average those captured in cages had over twice as many heterophils counted than those captured by noose, based on examination of the untransformed data (mean for cage $=18.3$ cells $/ 2000$ erythrocytes, mean for noose $=8.3$ cells $/ 2000$ erythrocytes $)$. Moreover, while there was no significant effect of trap type on the absolute numbers of lymphocytes $(t=1.36, d f=48, P=$ 0.178 ), the average number counted in cage-trapped iguanas was in fact lower than those caught via noose (Figure 4(b)). There was also a significant effect of trap type on the numbers of monocytes ( $t=-2.47, d f=48, P=0.017$; Figure $4(\mathrm{c})$ ) but no effect of trap type on the estimated numbers of basophils $(t=0.80, d f=48, P=0.427$; Figure $4(\mathrm{~d}))$.

\section{Discussion}

The central question in this study was whether estimated leukocyte counts of animals differed in directly captured animals or those captured with baited cage traps, and the results obtained are clear: the two methods do lead to at least some differences in the abundance of particular cell types in circulation. Given that the primary difference was in the relative and absolute counts of heterophils, which are known to increase with elevations in stress hormones (reviewed in [16]), the higher average count among cagetrapped animals could be interpreted as a result of the stress induced by remaining in the cage trap. Furthermore, while the difference was not significant, cage-trapped iguanas did have lower average estimated lymphocyte numbers than noosed animals, which is another sign of hormonally altered leukocyte populations. Surprisingly, the number of monocytes was also higher in cage-trapped animals, which at first glance might be interpreted as a general inflammation response [4]; however, inflammation and stress are tightly linked in animals [41-43], so it is possible that one could give rise to the other.

Although our interpretation of the data in this project is based on the known effect of stress on leukocytes in vertebrates (reviewed in [16]), and the known effect of cage traps on stress profiles of voles and birds $[14,15]$, one could in fact 


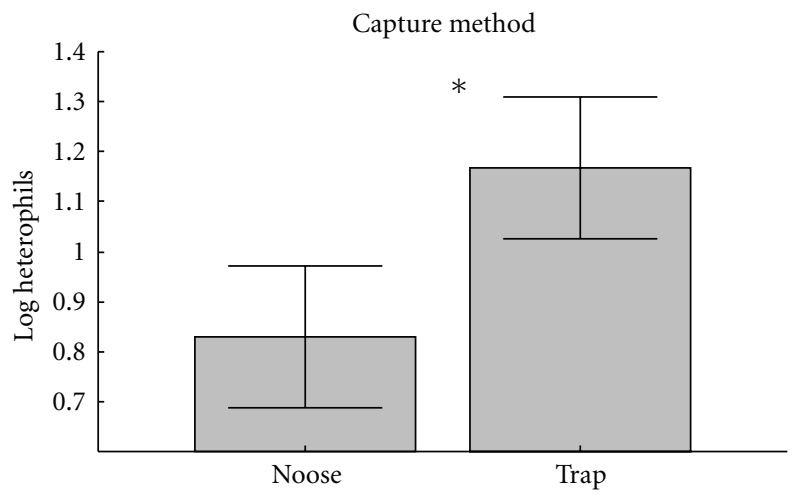

(a)

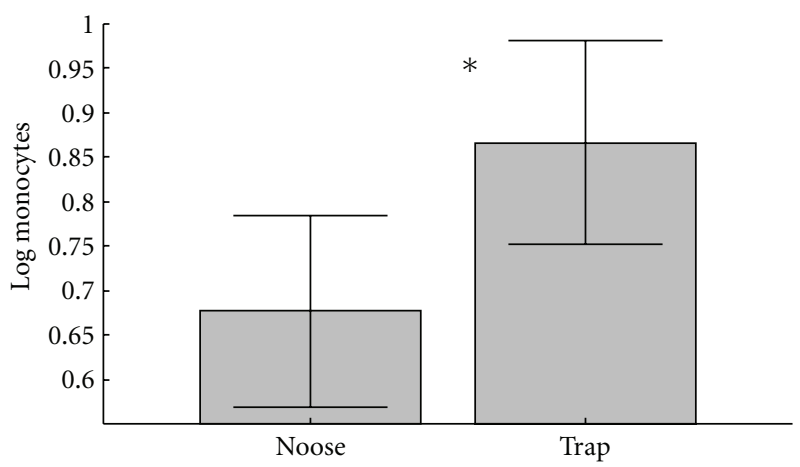

(c)

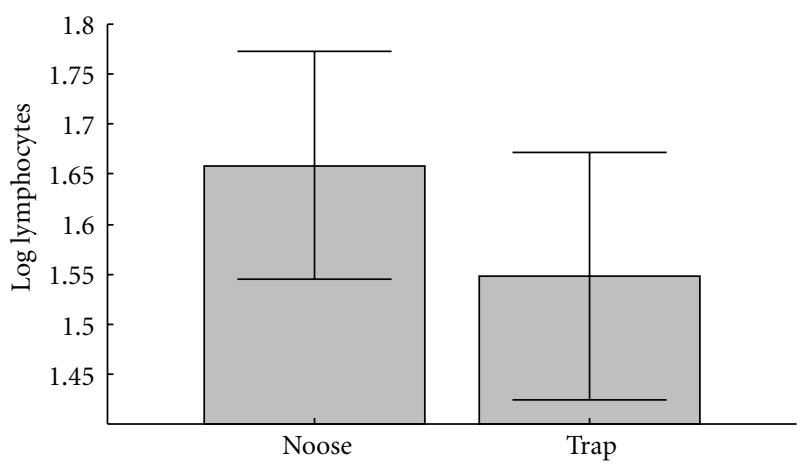

(b)

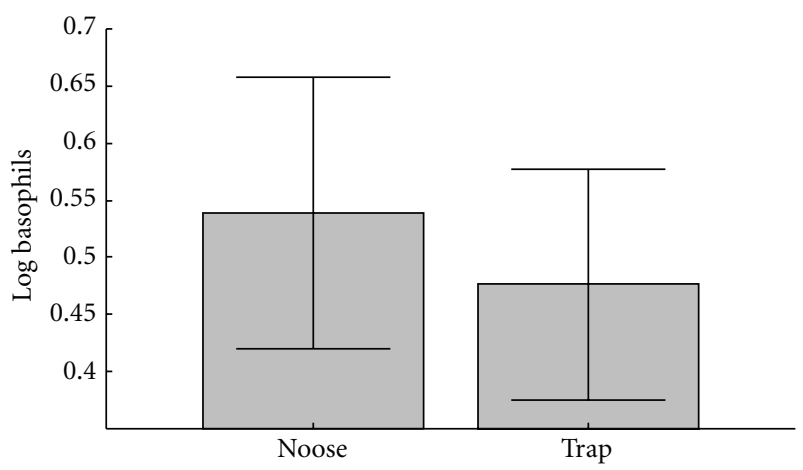

(d)

FIGURE 4: Average log-transformed counts of heterophils (a), lymphocytes (b), monocytes (c), and basophils (d) of iguanas captured with noose $(n=27)$ and by cage trap $(n=23)$. Bars represent $95 \%$ confidence intervals. Asterisks indicate significant differences based on Student's $t$-tests (see text).

interpret the patterns we observed in an alternative fashion; it may be that the two trapping schemes used here inherently sample different subsets of the iguana population, which may in turn have differing concentrations of selected cell types. While this idea seems unlikely, such a scenario has been shown in a species of songbird sampled with two different techniques [13] and in studies of small herpetofauna [12]. However, the analyses of the 10 iguanas for which we had two samples from (which demonstrated that $\mathrm{H}-\mathrm{L}$ ratios were higher in cage-trapped versus noosed animals) argues against this possibility.

Although we focused here on a reptile species, results from this study have considerable implications for researchers who capture most other wild animals for the purposes of obtaining leukocyte information, especially if the investigator is interested in knowing the baseline or resting levels of leukocytes in circulation. Indeed, this is often the case, both for ecologists (e.g., $[3,8,44])$, and for wildlife veterinarians conducting health surveys (e.g., [37, 45-47]). Clearly, the researcher must consider the choice of trap method and take into account the time that animals must spend in any given trap design before sampling. Based on our data, we suggest if the intent is to obtain the truest representation of the leukocyte picture of an animal, direct capture and immediate sampling (i.e., within minutes) is ideal. Even though trapping wild animals does initiate the release of stress hormones in most subjects within minutes [48], the effect of stress on the leukocyte populations generally takes a longer period of time to manifest [49]. In fact in ectothermic animals (reptiles, amphibians, and fish), the leukocyte response to stress is thought to take even longer to manifest (on the order of hours to days) than in endothermic animals because of their slower, temperature-dependent metabolism [16]. While the exact time frame for the response is not known (and may vary with ambient temperatures, or by species), given that iguanas in this study could have been in traps for up to four hours, it is clear that this time frame is sufficient to alter basal numbers of circulating leukocytes in this reptile species. Further study of this phenomenon is needed to elucidate the time course of stress-induced leukocyte alterations in both ectotherms and endotherms.

Given that iguanas and lizards are exceptionally well studied with respect to their white blood cell profiles, as an interesting followup to our field data we compiled published reports of related iguana species and other lizards and examined the concentrations of blood cells given (Table 2). For all published reports we had access to, we extracted the information given on the relative numbers of all cell types (mean percentages) and categorized the studies based on whether the animals were from captive sources (pets or zoos) or were wild. In doing so we discovered a clear pattern, in that all wild-caught animals studied appeared to have much 
TABLE 2: List of published reports of leukocytes of iguanas and other lizard species. Relative numbers of cells (\%) shown for each record. Records from wild-caught animals are shown in bold.

\begin{tabular}{|c|c|c|c|c|c|c|c|c|c|}
\hline Species & $N$ & Source & Lymph & Hetero & Eosin & Baso & Mono & $\mathrm{H}-\mathrm{L}$ & Source \\
\hline Green iguana (Iguana iguana) & 10 & Captive & 53.7 & 27.5 & 0.6 & 4.4 & 7.1 & 0.51 & [29] \\
\hline Green iguana (Iguana iguana) & 11 & Captive & 52.4 & 33.0 & 1.6 & 4.9 & 8.1 & 0.63 & {$[28]$} \\
\hline Green iguana (Iguana iguana) & 15 & Captive & 64.2 & 23.8 & 0.7 & 2.6 & 8.6 & 0.37 & {$[32]$} \\
\hline Green iguana (Iguana iguana) & 32 & Captive & 60.6 & 30.8 & 0.8 & 0.6 & 6.3 & 0.51 & {$[33]$} \\
\hline $\begin{array}{l}\text { Grand cayman blue iguana (Cyclura nubila } \\
\text { lewisi) }\end{array}$ & 10 & Captive & 40.0 & 35.0 & 2.0 & 15.0 & 3.0 & 0.88 & {$[27]$} \\
\hline Cuban Iguana (Cyclura nubila) & 26 & Captive & 79.7 & 9.7 & 1.4 & 5.4 & 4.0 & 0.12 & {$[34]$} \\
\hline $\begin{array}{l}\text { Chinese water dragon (Physignathus } \\
\text { cocincinus) }\end{array}$ & 12 & Captive & 53.3 & 37.7 & 1.5 & 3.7 & 8.1 & 0.71 & [35] \\
\hline Inland bearded dragon (Pogona vitticeps) & 21 & Captive & 59.0 & 27.0 & 0.0 & 9.0 & 5.0 & 0.46 & {$[36]$} \\
\hline Argentine tegu lizard (Tupinambis merianae) & 50 & Captive & 45.0 & 13.0 & 24.5 & 1.9 & 17.0 & 0.29 & {$[37]$} \\
\hline Cuban Iguana (Cyclura nubila) & 13 & Wild & 35.2 & 49.5 & 0.5 & 5.2 & 9.6 & 1.41 & {$[34]$} \\
\hline Spiny-tailed lizard (Uromastyx spp.) & 76 & Wild & 32.1 & 64.4 & 1.3 & 0.8 & 1.3 & 2.01 & {$[38]$} \\
\hline Spiny-tailed lizard (Uromastyx microlepis) & 24 & Wild & 21.0 & 72.0 & 1.0 & 0.0 & 6.0 & 3.43 & {$[36]$} \\
\hline Tenerife giant lizard (Gallotia intermedia) & 4 & Wild & 22.6 & 50.1 & 2.9 & 15.8 & 8.3 & 2.22 & [39] \\
\hline El Hierro giant lizard (Gallotia simonyi) & 9 & Wild & 13.6 & 39.0 & 3.7 & 20.5 & 22.7 & 2.87 & [39] \\
\hline La Gomera giant lizard (Gallotia bravoana) & 6 & Wild & 8.5 & 58.4 & 2.1 & 7.0 & 23.9 & 6.87 & [39] \\
\hline $\begin{array}{l}\text { Allen cays rock iguana (Cyclura cychlura } \\
\text { inornata) }\end{array}$ & 37 & Wild & 18.5 & 61.5 & 1.7 & 7.5 & 4.1 & 3.32 & {$[2]$} \\
\hline Chameleon (Chamaeleo chamaeleon) & 8 & Wild & 25.0 & 56.0 & 0.0 & 0.5 & 9.0 & 2.24 & [40] \\
\hline
\end{tabular}

higher $\mathrm{H}-\mathrm{L}$ ratios than the captive animals. This difference was significant in a Student's $t$-test $(d f=15, t=-4.5$, $P<0.001$ ). In fact, the relative abundance of lymphocytes and heterophils was completely opposite in both groups, with lymphocytes being most common cell type in captive lizards and heterophils most common in wild individuals (Table 2). Granted, each of these studies sampled different species of animals in different locations and different times of the year, so this comparison is admittedly crude. However, we point out that in one study in particular, blood cell data was compared directly from both free-ranging and captive iguanas (Cyclura nubila) and a similar trend was found [34]. From this information, two possible conclusions can be drawn-either wild lizards simply have naturally higher levels of stress (and correspondingly higher H-L ratios) than do captive lizards, or that the investigators in the wild studies trapped the animals in such a way as to induce stress-related alterations in the animals' leukocyte profiles. While both ideas are possible, the second scenario is more likely, which serves to emphasize the importance of the type of trap in hematological studies of wild animals.

In conclusion, results from this study revealed that animals captured in baited cage traps have leukocyte profiles that differ from those captured directly, in a manner consistent with the effects of stress hormones on white blood cell distributions. These data argue for caution in interpreting leukocyte data from studies of wild animals captured with cage traps or where the method of capture is not reported (or perhaps even where unusually high H-L ratios are seen), and they underscore the importance of designing trapping schemes that take this issue into account, especially if resting, or baseline concentrations of leukocytes are sought.

\section{Acknowledgments}

The authors thank the Honduran Coral Reef Foundation for their help and logistical support of the project. They appreciate the help of Alex Arturo Solis and Hector Garcia for assistance with field methods. They are also grateful to Vanessa Ezenwa for providing helpful comments on the paper.

\section{References}

[1] M. M. Christopher, K. H. Berry, I. R. Wallis, K. A. Nagy, B. T. Henen, and C. C. Peterson, "Reference intervals and physiologic alterations in hematologic and biochemical values of free-ranging desert tortoises in the mojave desert," Journal of Wildlife Diseases, vol. 35, no. 2, pp. 212-238, 1999.

[2] S. B. James, J. Iverson, V. Greco, and B. L. Raphael, "Health assessment of Allen Cays Rock Iguana, Cyclura cyclura inornata," Journal of Herpetological Medicine and Surgery, vol. 16, pp. 93-98, 2006.

[3] S. S. French, H. B. Fokidis, and M. C. Moore, "Variation in stress and innate immunity in the tree lizard (Urosaurus ornatus) across an urban-rural gradient," Journal of Comparative Physiology B, vol. 178, no. 8, pp. 997-1005, 2008.

[4] N. C. Jain, Essentials of Veterinary Hematology, Blackwell Publishing, Philadelphia, Pa, USA, 1993.

[5] S. L. Stockham and M. A. Scott, Fundamentals of Veterinary Clinical Pathology, Blackwell Publishing, Ames, Iowa, USA, 2002. 
[6] T. W. Campbell and C. K. Ellis, Avian and Exotic Animal Hematology and Cytology, Blackwell Publishing, Ames, Iowa, USA, 2007.

[7] A. Camplani, N. Saino, and A. P. Møller, "Carotenoids, sexual signals and immune function in barn swallows from Chernobyl," Proceedings of the Royal Society B, vol. 266, no. 1424, pp. 1111-1116, 1999.

[8] J. Moreno, S. Merino, J. Martínez, J. J. Sanz, and E. Arriero, "Heterophil/lymphocyte ratios and heat-shock protein levels are related to growth in nestling birds," Ecoscience, vol. 9, no. 4, pp. 434-439, 2002.

[9] D. D. Forson and A. Storfer, "Atrazine increases ranavirus susceptibility in the tiger salamander, Ambystoma tigrinum," Ecological Applications, vol. 16, no. 6, pp. 2325-2332, 2006.

[10] T. R. Raffel, J. R. Rohr, J. M. Kiesecker, and P. J. Hudson, "Negative effects of changing temperature on amphibian immunity under field conditions," Functional Ecology, vol. 20, no. 5, pp. 819-828, 2006.

[11] A. K. Davis and A. M. Durso, "White blood cell differentials of northern cricket frogs (Acris c. crepitans) with a compilation of published values from other amphibians," Herpetologica, vol. 65, no. 3, pp. 260-267, 2009.

[12] C. H. Greenberg, D. G. Neary, and L. D. Harris, "A comparison of herpetofaunal sampling effectiveness of pitfall, singleended, and double-ended funnel traps used with drift fences," Journal of Herpetology, vol. 28, no. 3, pp. 319-333, 1994.

[13] A. K. Davis, "A comparison of age, size, and health of House Finches captured with two trapping methods," Journal of Field Ornithology, vol. 76, no. 4, pp. 339-344, 2005.

[14] Q. E. Fletcher and R. Boonstra, "Impact of live trapping on the stress response of the meadow vole (Microtus pennsylvanicus)," Journal of Zoology, vol. 270, no. 3, pp. 473-478, 2006.

[15] S. E. Lynn and A. J. Porter, "Trapping initiates stress response in breeding and non-breeding house sparrows Passer domesticus: implications for using unmonitored traps in field studies," Journal of Avian Biology, vol. 39, no. 1, pp. 87-94, 2008.

[16] A. K. Davis, D. L. Maney, and J. C. Maerz, "The use of leukocyte profiles to measure stress in vertebrates: a review for ecologists," Functional Ecology, vol. 22, no. 5, pp. 760-772, 2008.

[17] L. J. Buckley and R. W. Axtell, "Evidence for the specific status of the Honduran Lizards formerly referred to Ctenosaura palearis (Reptilia: Squamata: Iguanidae)," Copeia, no. 1, pp. 138 150, 1997.

[18] E. Bermingham, A. Coates, G. Cruz Diaz et al., "Geology and terrestrial flora and fauna of Cayos Cochinos, Honduras," Revista de Biologia Tropical, vol. 46, supplement 4, pp. 15-37, 1998.

[19] W. J. Sutherland, Ecological Census Techniques: A Handbook, Cambridge University Press, Cambridge, UK, 2006.

[20] R. Maria, J. Ramer, T. Reichard, P. J. Tolson, and M. M. Christopher, "Biochemical reference intervals and intestinal microflora of free-ranging Ricord's iguanas (Cyclura ricordii)," Journal of Zoo and Wildlife Medicine, vol. 38, no. 3, pp. 414419, 2007.

[21] B. Houwen, "Blood film preparation and staining procedures," Laboratory Hematology, vol. 6, pp. 1-7, 2000.

[22] A. K. Davis and J. C. Maerz, "Sex-related differences in hematological stress indices of breeding paedomorphic mole salamanders," Journal of Herpetology, vol. 42, no. 1, pp. 197-201, 2008.
[23] A. K. Davis and J. C. Maerz, "Comparison of hematological stress indicators in recently captured and captive paedomorphic Mole Salamanders, Ambystoma talpoideum," Copeia, no. 3, pp. 613-617, 2008.

[24] A. K. Davis, "Metamorphosis-related changes in leukocyte profiles of larval bullfrogs (Rana catesbeiana)," Comparative Clinical Pathology, vol. 18, no. 2, pp. 181-186, 2009.

[25] M. A. Thrall, "Hematology of reptiles," in Veterinary Hematology and Clinical Chemistry: Text and Clinical Case Presentations, M. A. Thrall, D. C. Baker, and E. D. Lassen, Eds., Lippincott Williams \& Wilkins, Philadelphia, Pa, USA, 2004.

[26] A. R. Alleman, E. R. Jacobson, and R. E. Raskin, "Morphologic and cytochemical characteristics of blood cells from the desert tortoise (Gopherus agassizii)," American Journal of Veterinary Research, vol. 53, no. 9, pp. 1645-1651, 1992.

[27] A. Fisse, M. Draud,, B. Raphael, and K. Melkonian, "Differential leukocyte counts of critically endangered grand cayman blue iguanas, Cyclura nubila lewisi," Journal of Herpetological Medicine and Surgery, vol. 14, no. 4, pp. 19-21, 2004.

[28] S. Pejřilova, Z. Knotková, Z. Knotek, and V. Vrbas, "Agerelated changes of the haematological profile in green iguana (Iguana iguana rhinolopha)," Acta Veterinaria Brno, vol. 73, no. 3, pp. 305-312, 2004.

[29] Z. Knotkova, Z. Knotek, S. Trnkova, and P. Mikulcova, "Blood profile in green iguanas after short-term anaesthesia with propofol," Veterinarni Medicina, vol. 51, no. 10, pp. 491-496, 2006.

[30] M. Tavares-Dias, A. A. Oliveira, and J. L. Marcon, "Methodological limitations of counting total leukocytes and thrombocytes in reptiles (Amazon turtle, Podocnemis expansa): an analysis and discussion," Acta Amazonica, vol. 38, no. 2, pp. 351-355, 2008.

[31] Statistica, “Statistica version 6.1," Statsoft, 2003.

[32] K. E. Harr, A. R. Alleman, P. M. Dennis et al., "Morphologic and cytochemical characteristics of blood cells and hematologic and plasma biochemical reference ranges in green iguanas," Journal of the American Veterinary Medical Association, vol. 218, no. 6, pp. 915-921, 2001.

[33] C. S. Hanley, S. J. Hernandez-Divers, S. Bush, and K. S. Latimer, "Comparison of the effect of dipotassium ethylenediaminetetraacetic acid and lithium heparin on hematologic values in the green iguana (Iguana iguana)," Journal of Zoo and Wildlife Medicine, vol. 35, no. 3, pp. 328-332, 2004.

[34] A. C. Alberts, M. L. Oliva, M. B. Worley, S. R. Telford, P. J. Morris, and D. L. Janssen, "The need for pre-release health screening in animal translocations: a case study of the Cuban iguana (Cyclura nubila)," Animal Conservation, vol. 1, no. 3, pp. 165-172, 1998.

[35] J. Mayer, J. Knoll, C. Innis, and M. A. Mitchell, “Characterizing the hematologic and plasma chemistry profiles of captive Chinese water dragons, Physignathus oncincinus," Journal of Herpetological Medicine and Surgery, vol. 15, pp. 16-23, 2005.

[36] M. M. Eliman, "Hematology and plasma chemistry of the inland bearded dragon, Pogona vitticeps," Bulletin of the Association of Reptile and Amphibian Veterinarians, vol. 7, no. 4, 1997.

[37] J. C. Troiano, E. G. Gould, and I. Gould, "Hematological reference intervals in argentine lizard Tupinambis merianae (Sauria-Teiidae)," Comparative Clinical Pathology, vol. 17, no. 2, pp. 93-97, 2008.

[38] J. L. Naldo, N. L. Libanan, and J. H. Samour, "Health assessment of a spiny-tailed lizard (Uromastyx spp.) population in Abu Dhabi, United Arab Emirates," Journal of Zoo and Wildlife Medicine, vol. 40, no. 3, pp. 445-452, 2009. 
[39] A. M. Silvestre, M. A. R. Domínguez, J. A. Mateo et al., "Comparative haematology and blood chemistry of endangered lizards (Gallotia species) in the Canary Islands," Veterinary Record, vol. 155, no. 9, pp. 266-269, 2004.

[40] M. Cuadrado, C. Díaz-Paniagua, M. A. Quevedo, J. M. Aguilar, and I. M. Prescott, "Hematology and clinical chemistry in dystocic and healthy post-reproductive female chameleons," Journal of Wildlife Diseases, vol. 38, no. 2, pp. 395-401, 2002.

[41] A. K. Davis, K. C. Cook, and S. Altizer, "Leukocyte profiles in wild House Finches with and without mycoplasmal conjunctivitis, a recently emerged bacterial disease," Ecohealth, vol. 1, no. 4, pp. 362-373, 2004.

[42] K. M. Lindström, D. M. Hawley, A. K. Davis, and M. Wikelski, "Stress responses and disease in three wintering house finch (Carpodacus mexicanus) populations along a latitudinal gradient," General and Comparative Endocrinology, vol. 143, no. 3, pp. 231-239, 2005.

[43] A. K. Davis, M. K. Keel, A. Ferreira, and J. C. Maerz, "Effects of chytridiomycosis on circulating white blood cell distributions of bullfrog larvae (Rana catesbeiana)," Comparative Clinical Pathology, vol. 19, no. 1, pp. 49-55, 2010.

[44] P. Kilgas, V. Tilgar, and R. Mänd, "Hematological health state indices predict local survival in a small passerine bird, the great tit (Parus major)," Physiological and Biochemical Zoology, vol. 79, no. 3, pp. 565-572, 2006.

[45] S. Lavin, R. Cuenca, I. Marco, R. Velarde, and L. Vinas, "Hematology and blood chemistry of the marsh harrier (Circus aeruginosus)," Comparative Biochemistry and Physiology, vol. 103, no. 3, pp. 493-495, 1992.

[46] J. Zaias, T. Norton, A. Fickel, J. Spratt, N. H. Altman, and C. Cray, "Biochemical and hematologic values for 18 clinically healthy radiated tortoises (Geochelone radiata) on St Catherines Island, Georgia," Veterinary Clinical Pathology, vol. 35, no. 3, pp. 321-325, 2006.

[47] M. E. Solís, J. M. Bandeff, and Y. W. Huang, "Hematology and serum chemistry of Ozark and eastern hellbenders (Cryptobranchus alleganiensis)," Herpetologica, vol. 63, no. 3, pp. 285 292, 2007.

[48] L. M. Romero and J. M. Reed, "Collecting baseline corticosterone samples in the field: is under $3 \mathrm{~min}$ good enough?" Comparative Biochemistry and Physiology, vol. 140, no. 1, pp. 73-79, 2005.

[49] A. K. Davis, "Effect of handling time and repeated sampling on avian white blood cell counts," Journal of Field Ornithology, vol. 76, no. 4, pp. 334-338, 2005. 

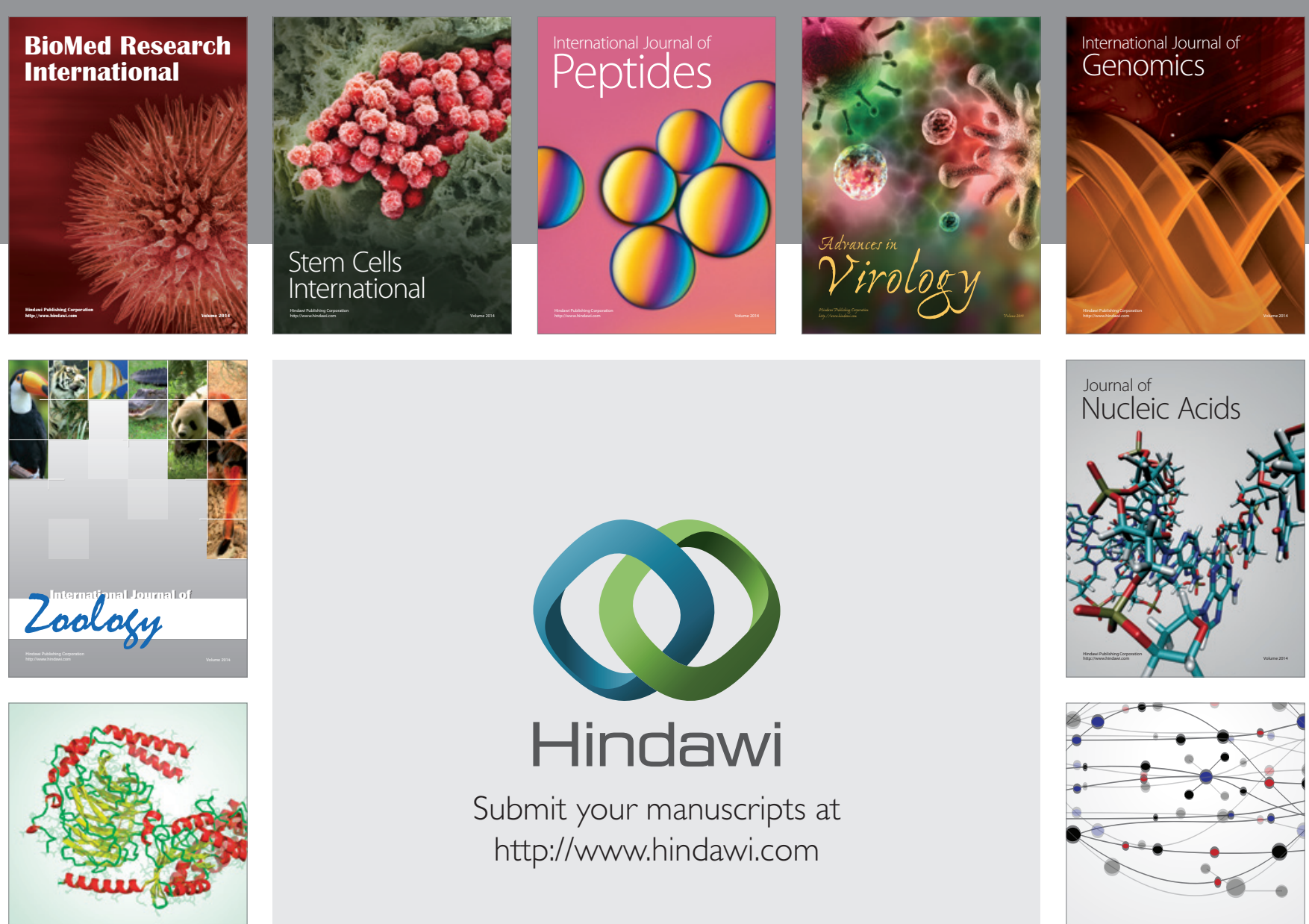

Submit your manuscripts at

http://www.hindawi.com

Signal ${ }^{\text {Jumal }}$ Transduction
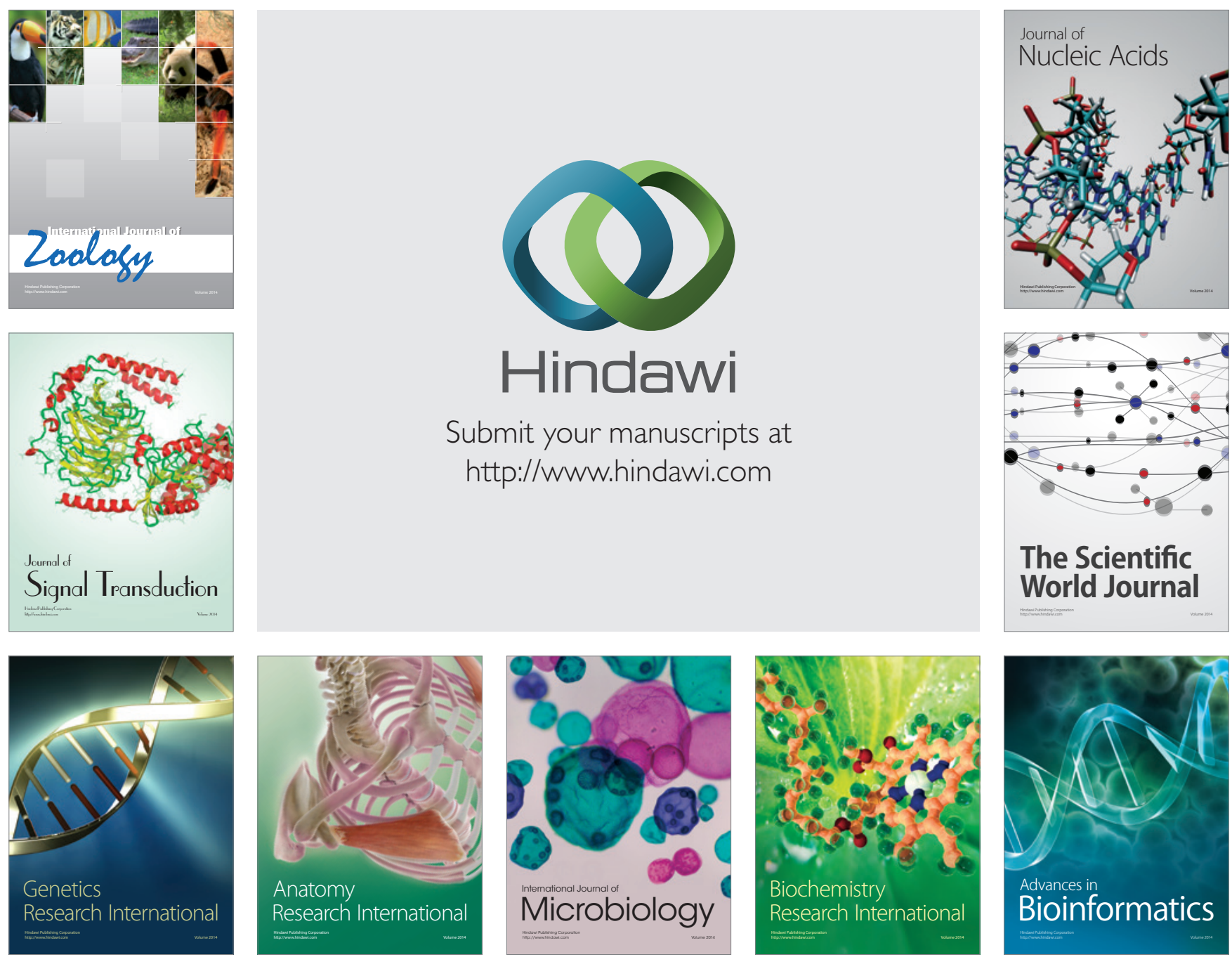

The Scientific World Journal
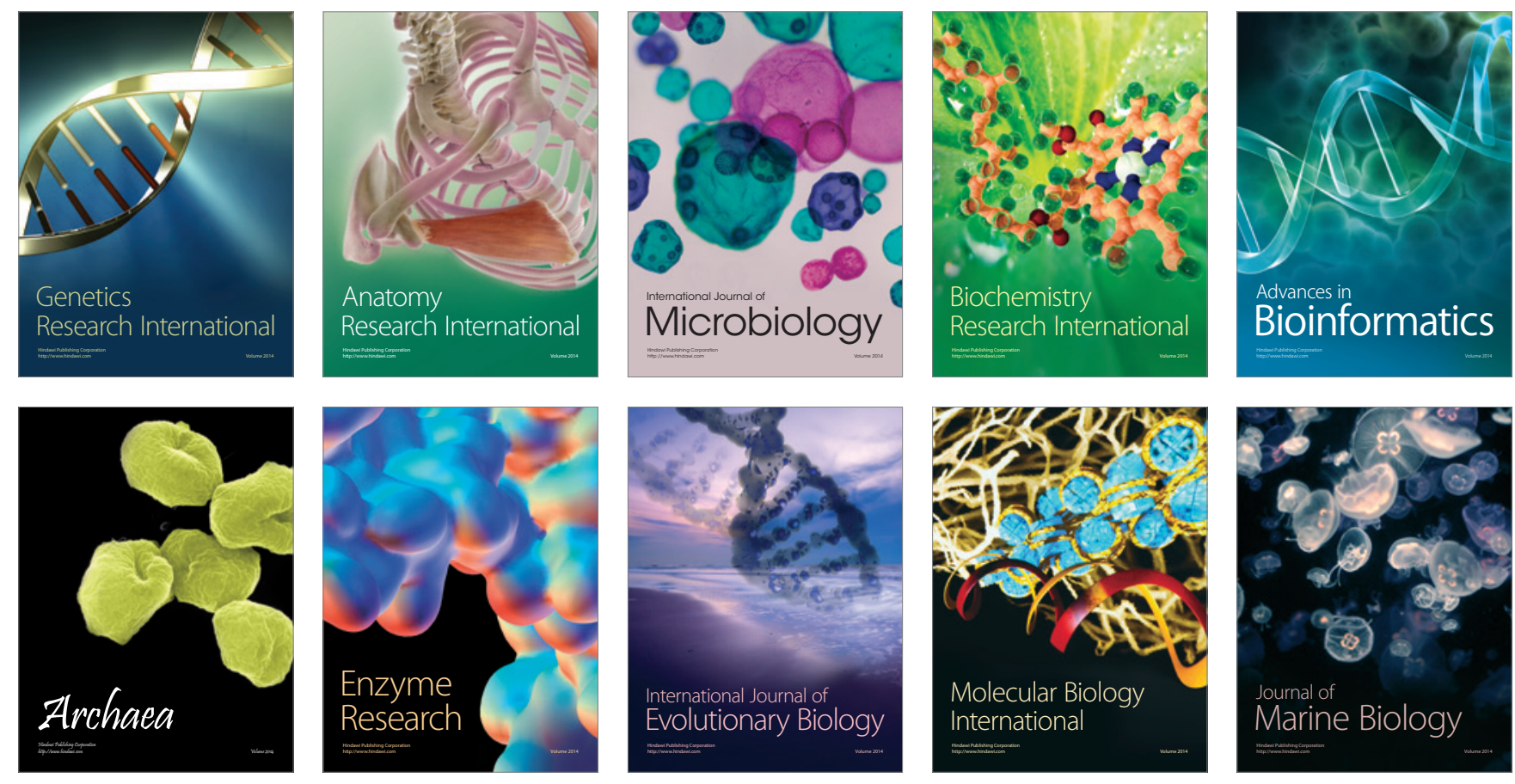